\title{
The spatial variability of air temperature and nocturnal urban heat island intensity in the city of Brno, Czech Republic
}

\author{
Petr DOBROVOLNÝ a*, Lukáš KRAHULA a
}

\begin{abstract}
This study seeks to quantify the effects of a number of factors on the nocturnal air temperature field in a medium-sized central European city located in complex terrain. The main data sources consist of mobile air temperature measurements and a geographical database. Temperature measurements were taken along several profiles through the city centre and were made under a clear sky with no advection. Altogether nine sets of detailed measurements, in all seasons, were assembled. Altitude, quantity of vegetation, density of buildings and the structure of the transportation (road) system were considered as explanatory variables. The result is that the normalized difference vegetation index (NDVI) and the density of buildings were the most important factors, each of them explaining a substantial part (more than 50\%) of overall air temperature variability. Mobile measurements with NDVI values as a covariate were used for interpolation of air temperature for the entire study area. The spatial variability of nocturnal air temperature and UHI intensity in Brno is the main output presented. Air temperatures interpolated from mobile measurements and NDVI values indicate that the mean urban heat island (UHI) intensity in the early night in summer is at its highest (approximately $5^{\circ} \mathrm{C}$ ) in the city centre and decreases towards the suburban areas.
\end{abstract}

Keywords: urban heat island, mobile measurements, air temperature, Brno, Czech Republic

\section{Introduction}

The urban heat island is possibly the most important specific characteristic of urban climate, a phenomenon that relates to the higher temperatures that prevail in urban areas compared to the surrounding rural environment (Arnfield, 2003). No matter how the intensity of UHI is defined (Stewart, 2011), the same general set of factors create UHI and influence its intensity. Local geography, prevailing categories of land use and their spatial distribution, the thermal properties of materials used for surfaces and buildings, the geometry of the constructions themselves, and anthropogenic heat production are among the most important of these (Landsberg, 1981; Oke, 1981; Grimmond, 2006). The role and importance of individual factors may differ significantly from city to city, however, depending on geographical position, size, number of inhabitants, etc. More specific knowledge of the most important factors impacting upon UHI intensity may contribute significantly to mitigation of its negative effects. Such effects are largely related to the occurrence of heat waves that may be of longer duration and more intense in an urban climate, with direct impacts on human health (Kyselý, 2010; Dousset et al., 2011), including increasing urban fatalities (Peng et al., 2011; Laidii et al., 2012).

Air temperature in urban areas and UHI intensity vary widely in time and space. Whereas the highest positive intensity of atmospheric UHI occurs during the night, UHI may be weakly expressed during daylight hours, or even negative, due to shadowing effects (Hart and Sailor, 2009). Other factors, however, such as land-cover and availability of soil moisture may contribute to negative UHI (Georgescu et al., 2011). The spatial distribution of air temperatures in urban areas is highly complicated, as is the spatial structure of UHI intensity. Most of the factors that modify energy balance and air temperature conditions in cities arise out of the highly different thermal properties of the urban environment relative to its natural surroundings. Improved knowledge of the spatial distribution of air temperature in urban areas and UHI intensity may be achieved by consideration of two elements in particular: spatially-detailed air temperature measurements, together with a detailed spatial database of the factors affecting urban air temperatures.

Standard meteorological measurements, even supplemented by special-purpose measurements from a dense network of automatic stations, often prove insufficient to describe and understand fully the spatial variability of air temperature in urban areas (Hart and Sailor, 2009; Dobrovolný and Krahula, 2012). Some of the limitations of stationary measurements may be overcome by various types of mobile measurement made by thermometers attached to vehicles. The first systematic mobile measurements were taken in Vienna as early as 1927 (Yoshino, 1984). These methods were further developed in Sweden (Sundborg, 1950), and in Czechoslovakia, Quitt (1972) used thermometers mounted on automobiles and trams to record air temperature variability in the city of Brno (now the Czech Republic). Recently, Unger et al. (2001) and Bottyán et al. (2005) used mobile measurements to investigate temperature conditions in the Hungarian cities of Szeged and Debrecén. Hedquist and Brazel (2006) compared the results of stationary and mobile temperature measurements in Phoenix, Arizona (USA). Hart and Sailor (2009) analysed the spatial variability of air temperature in terms of both land use and a number of surface characteristics in Portland (USA) by means of regression trees applied to the results of

\footnotetext{
a Department of Geography, Faculty of Science, Masaryk University, Brno, Czech Republic (*corresponding author: P. Dobrovolný, e-mail: dobro@sci.muni.cz)
} 
mobile measurements. Mobile campaigns have a particular advantage over a network of stations when analysing the spatial variability of urban climate, since mobile traverses provide a significantly higher density of measurements and thus offer better initial conditions for more precise spatial interpolation. The higher number of measuring points is rendered all the more valuable in urban environments of high heterogeneity.

In this contribution, mobile temperature measurements taken in the medium-scale city of Brno are analysed. The study aims to establish the main factors that correlate with air temperature measurements; the air temperatures and these covariates are then used to construct the urban temperature field. Finally, the nocturnal UHI intensity in the study area is estimated.

\section{Study area and data}

The study area is situated in the south-eastern part of the Czech Republic (Fig. 1). Brno (49.2N, 16.5E) is the secondlargest city in the country (population 400,000, cadastral area $230 \mathrm{~km}^{2}$ ), and is characterized by a basin position with complex terrain. Altitudes range from $190 \mathrm{~m}$ to $479 \mathrm{~m}$, with the higher elevations lying largely in the western and northern parts of the region. Lower and flatter terrain is typical of the southern and eastern parts of the study area. There is a large water reservoir (area approximately $2.6 \mathrm{~km}^{2}$ ) located on the north-west border of the built-up part. The study area lies in one of the warmest and the driest regions in the Czech Republic. Mean annual temperature stands at $9.4{ }^{\circ} \mathrm{C}$, while mean annual precipitation is around $500 \mathrm{~mm}$ (1961-2000 reference period).

The city's location at the confluence of two rivers and a complex relief with several deep valleys and hills predispose the area to a complicated spatial distribution of land-cover categories. The highest density of built-up areas occurs in the historical city centre. These are largely residential
(20\% of the cadastral area). There are several industrial zones and large shopping centres with high percentages of impervious surfaces (area almost 14\% of total). Several large parks are located relatively close to the city centre. Further from the centre, individual land-cover categories form a mosaic of different surface types, such as blocks of flats, gardens, allotments and agricultural fields. Arable land and grasslands cover $34 \%$ of the study cadastre and are situated mostly in the south, while forests take up $29 \%$ of the cadastre and are to be found largely west and north of the built-up area, at higher elevations. Percentages of individual land use categories were calculated from interpreted LANDSAT satellite imagery at an original spatial resolution of $30 \mathrm{~m}$ (Dobrovolný, 2012).

Mobile air temperature measurements were taken along a number of profiles that ran though the city centre and also in various suburban environments (Fig. 1). Altogether, nine sets of measurements were made between April 2011 and January 2012, covering every season. Each set of measurements was around $90 \mathrm{~km}$ in length and lasted 3.5 hours. Elevation varied along the profile from $200 \mathrm{~m}$ to $410 \mathrm{~m}$. Since the most distinct air temperature differences between urban and rural environments start to build up in the early hours of the night (Oke, 1981; Alcoforado and Andrade, 2006; Fortuniak et al., 2006), measurements were taken at this time. A special resistance thermometer, featuring a $\mathrm{NiCr}-\mathrm{Ni}$ sensor with a rapid response time of 0.8 second for up to $90 \%$ of temperature change, was employed. The sensor was mounted on the left of an automobile, on the roof, approximately $1.8 \mathrm{~m}$ above ground level. Air temperature was recorded every five seconds. At a mean vehicle velocity of $30-40 \mathrm{~km} . \mathrm{h}^{-1}$ and in view of the length of the profile, each set of measurements comprised approximately 2,000 temperature readings taken at 40-50-metre intervals. The precise position of the automobile was recorded by GPS synchronized with the thermometer over time.

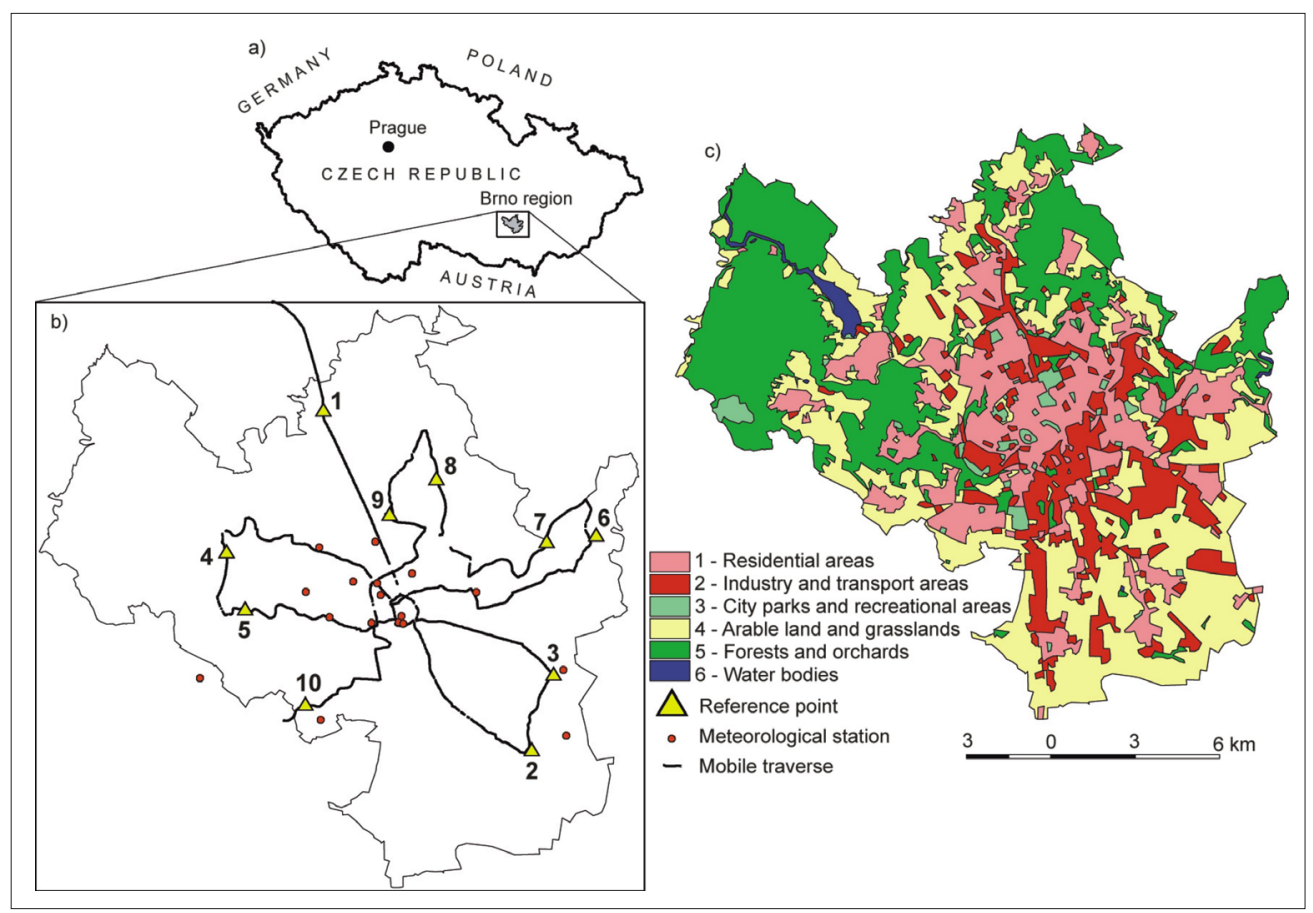

Fig. 1: Study area: a) position of Brno in the Czech Republic; b) route followed when taking mobile measurements; c) main land cover categories. Triangles 1-10 mark the beginning/end of sections with prevailing character of land cover type and serve for orientation within the measurement profiles (see Fig. 2).

Source: authors' calculations 


\section{Methods}

Raw measured air temperature data and GPS coordinates were pre-processed to suppress possible sources of noise. First, the general drop in temperature over time that occurred during the period of measurement was controlled for, using 10-minute-interval temperature readings from 16 special-purpose meteorological stations located in the Brno area (Fig. 1, selected stations - see Fig. 2 in cover p. 2). Station temperature measurements were taken at two metres above ground level, slightly higher $(0.2 \mathrm{~m})$ compared to the mobile measurements. A simple linear regression equation was fitted to each station air temperature at the time mobile measurements were being taken. The slopes of the regression lines for all stations were averaged and the mean regression coefficient then represented mean temperature drop per time unit (correction factor). By multiplying raw measured temperatures by time interval from the beginning of the mobile measurements, and using the correction factor, we conrolled for any general drop in temperature over time. One may assume that there may be a strong vertical gradient on quiet nights that may introduce differences between mobile and station measurements. As the slope of the regression line was used as a correction factor and not absolute temperature values, however, the above-mentioned $0.2 \mathrm{~m}$ height difference should not influence the results. Precise coordinates from GPS measurements were used to remove all temperature readings that had been taken at obligatory stops at traffic lights and crossroads, which might have been influenced by surrounding traffic, or were otherwise rendered redundant. Because certain GPS measurements proved impossible for a number of segments near the city centre with tall buildings, these were interpolated by calculations from the number of temperature readings and the topographical map. Finally, time-corrected temperatures were smoothed with a 3-point average filter to further suppress noise related to the high sensitivity of the sensor and random influences from the surrounding environment.

The factors that affect air temperature variability in the urban environment were described in terms of four variables. The degree of urbanization and extent of impervious surfaces were expressed as density of buildings (BUILD) and density of roads (RDS). The normalized difference vegetation index (NDVI) quantified the occurrence of natural pervious surfaces. The natural environment was also characterized by altitude (ALT). These parameters were included because they have been used successfully in similar studies (see for example: Unger et al., 2001; Bottyán et al., 2005; Hart and Sailor, 2009). Moreover, these parameters cover the study area continuously, which is important for subsequent spatial interpolation of an urban temperature field. Other parameters, such as anthropogenic heat and sky view factor, were not included since their values were available for only a few locations. The study area was divided into a regular grid of $300 \times 300 \mathrm{~m}$ and values for the above factors were calculated for each $300-\mathrm{m}$ grid cell. The ZABAGED geographical database, provided by the Czech Office for Surveying, Mapping and Cadastre (www.cuzk.cz), a digitalized topographical map at 1:10 000 scale, was employed for input data. The density of buildings was expressed as a percentage derived from the ground plan area of buildings in each grid cell. Similarly, RDS consisted of the overall area of the roads in each grid cell. NDVI was calculated from available LANDSAT TM satellite imagery, combining visible red and near-infra-red bands in a standard formula that may be found elsewhere (Dobrovolný, 2012). Because NDVI is a suitable measure of the quantity and vigour of vegetation, it is frequently used in urban climate studies to characterize the spatial distribution of pervious natural surfaces in a city environment (Dousset et al., 2003; Weng, 2009). The mean elevation of each grid cell (ALT) was calculated from an elevation model derived from the topographical map.

The size of the grid ( $300 \mathrm{~m}$ square) was chosen with reference to similar studies. According to Oke (2006), the circle of influence of environmental parameters, such as building density, upon temperature measurements may have a radius of about $0.5 \mathrm{~km}$, depending on local conditions. Unger (2004) characterized relationships between surface geometry and the urban heat island in Szeged (Hungary) with a 500-m grid, and Hart and Sailor (2009) quantified the influence of land-use and surface characteristics on urban temperatures in Portland (USA) using a $300-\mathrm{m}$ grid. Sampling at a $300-\mathrm{m}$ grid size was also selected for this study in view of the relatively high heterogeneity of the environment, especially in the suburbs (Fig. 3).

To evaluate the relative importance of individual factors for the spatial variability of air temperature, corrected temperatures from mobile measurements were aggregated to the same $300-\mathrm{m}$ grid. Mean temperature for each $300-\mathrm{m}$ grid cell through which the measurement profile passed was calculated as a simple arithmetical mean from all temperature readings performed within this grid-cell. The degree of temperature variance explained by individual factors was assessed by correlation analysis. Significant covariates were further used for spatial interpolation using geostatistical methods. The compiled air temperature fields were transformed to temperature anomalies that facilitated calculation of the intensity of UHI. As there was a clear correlation structure within some of the factors under consideration, their combinations and/or their principal component (PC) transformations were also tested for the extent of explained variance and for air temperature field construction.

\section{Results}

As follows from Table 1, each measurement campaign took place after sunset during the first half of night, in radiationdriven weather conditions. These were characterised by an almost clear sky, minimum cloud cover, and weak advection (Tab. 1). Such conditions are generally favourable to UHI formation. All four seasons were covered with at least two campaigns, providing a broad range of temperature regimes within the study area. Mean air temperatures during traverses varied from $-8.0^{\circ} \mathrm{C}$ at the end of January to $22.0^{\circ} \mathrm{C}$ in July. While relative variability was at its lowest in summer, it was highest in November and January. Air temperatures along the profiles varied by $5.0{ }^{\circ} \mathrm{C}-6.0^{\circ} \mathrm{C}$ in the winter months and by more than $10.0^{\circ} \mathrm{C}$ in July.

In spite of very different temperature conditions for individual days, several common features emerged from the temperature records from all campaigns (Fig. 4). In particular, three air temperature profiles from the first three segments $(1-2,3-4,5-6)$, which traversed the city centre, exhibit the convex shapes typical of positive UHI, with higher temperatures in the city centre and distinctly lower temperatures in suburban areas with higher percentages of natural surfaces. Conversely, segments traversing typically rural conditions $(2-3,4-5,6-7)$ exhibited lower temperatures. The minimum temperatures for each period were recorded at the beginning of the route, 

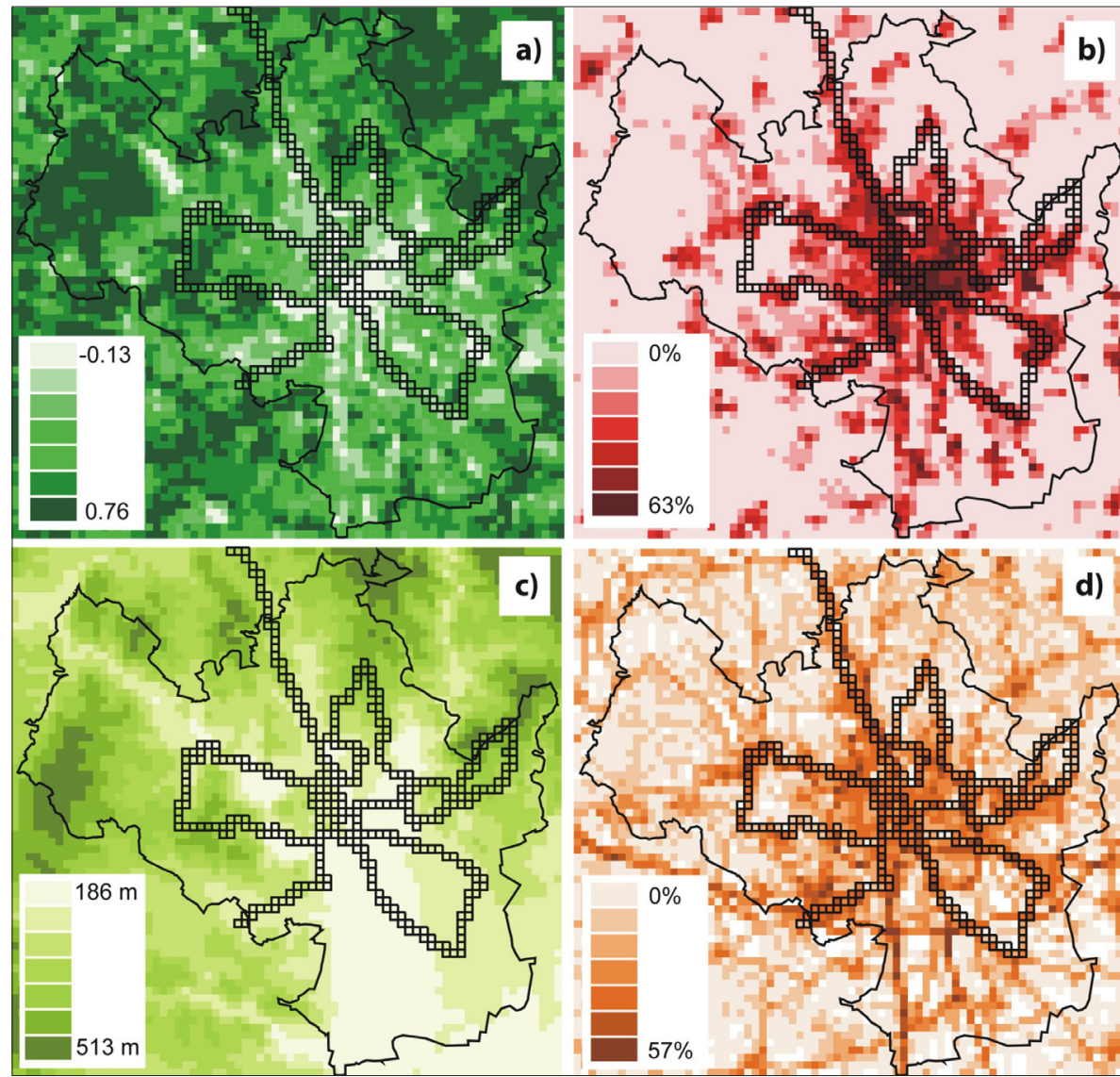

c)

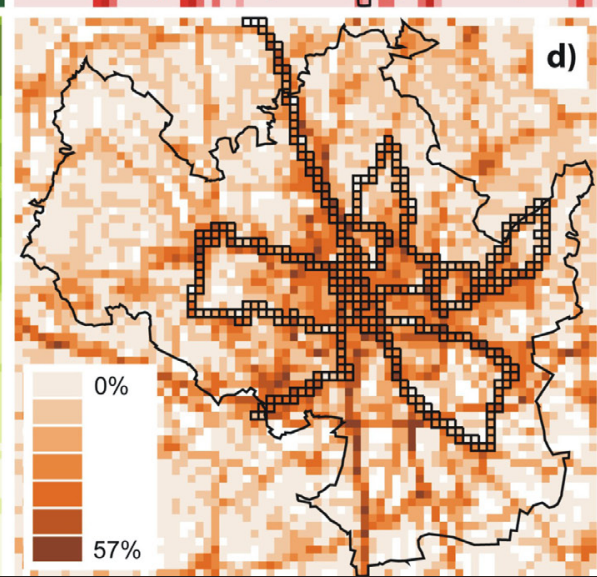

Fig. 3: Spatial distribution of selected factors affecting air temperature variability in the Brno area: a) Normalized difference vegetation index (NDVI); b) density of buildings (BUILD); c) altitude above sea level (ALT); d) density of roads (RDS). The solid black line delimits the Brno cadastral area. Source: authors' calculations

\begin{tabular}{|c|c|c|c|c|c|c|c|c|c|c|}
\hline Day & $\begin{array}{l}\text { Time } \\
\text { (h:min) }\end{array}$ & $\begin{array}{l}\text { Cloud cover } \\
\text { [tenths] }\end{array}$ & $\begin{array}{c}\text { Wind speed } \\
{\left[\mathrm{m} \cdot \mathrm{s}^{-1}\right]}\end{array}$ & $\begin{array}{c}\text { Wind } \\
\text { direction } \\
\text { [deg.] }\end{array}$ & $\begin{array}{l}\mathbf{t}_{\text {avg }} \\
{\left[{ }^{\circ} \mathbf{C}\right]}\end{array}$ & $\begin{array}{l}\mathbf{t}_{\min } \\
{\left[{ }^{\circ} \mathbf{C}\right]}\end{array}$ & $\begin{array}{l}\mathbf{t}_{\max } \\
{\left[{ }^{\circ} \mathbf{C}\right]}\end{array}$ & $\begin{array}{c}\mathbf{t}_{\text {range }} \\
{\left[{ }^{\circ} \mathbf{C}\right]}\end{array}$ & $\begin{array}{l}\mathbf{S D}^{* *} \\
{\left[{ }^{\circ} \mathbf{C}\right]}\end{array}$ & $\begin{array}{c}\mathbf{C V}^{* *} \\
{[\%]}\end{array}$ \\
\hline 19.4 .2011 & $20: 31-23: 28$ & 1 & 4 & 360 & 13.5 & 7.5 & 16.4 & 8.9 & 1.5 & 11.1 \\
\hline 9.5 .2011 & $20: 15-23: 04$ & 0 & 3 & 30 & 16.2 & 10.3 & 19.5 & 9.2 & 1.9 & 11.8 \\
\hline 8.7 .2011 & $20: 58-23: 54$ & 1 & 3 & 60 & 22.0 & 16.3 & 26.0 & 10.6 & 1.6 & 7.2 \\
\hline 3.8.2011 & $20: 21-23: 40$ & 1 & 3 & 40 & 21.1 & 15.8 & 24.0 & 8.2 & 1.4 & 6.8 \\
\hline 13.9.2011 & 20:12-23:03 & 2 & 1 & 260 & 21.2 & 15.6 & 24.5 & 8.9 & 1.6 & 7.7 \\
\hline 27.9.2011 & 20:03-23:19 & 1 & 1 & 350 & 17.3 & 12.6 & 20.0 & 7.4 & 1.5 & 8.6 \\
\hline 1.11 .2011 & $20: 28-23: 53$ & 1 & 2 & 70 & 5.7 & 1.9 & 8.4 & 6.4 & 1.2 & 21.6 \\
\hline 3.1.2012 & $20: 11-23: 28$ & 4 & 2 & 180 & 3.6 & 0.1 & 5.1 & 5.0 & 0.8 & 22.4 \\
\hline 31.1 .2012 & $20: 24-23: 54$ & 0 & 1 & 70 & -8.0 & -12.2 & -5.6 & 6.5 & 1.0 & 12.2 \\
\hline
\end{tabular}

Tab. 1: Basic information related to individual mobile measurements recorded in the Brno area*

Source: authors' calculations

Notes: *The time period refers to Central European Summer Time; data on cloud cover, wind speed and wind direction are means for the time period of the traverses recorded at the meteorological station at Brno, Turany airport. **SD-standard deviation; $C V$ - coefficient of variance

the farthest segment of the route from the urban area, and especially at the end of the route (beyond point No. 10 in Fig. 4). Here the lowest temperatures are related to the basin position of the locality and to conditions favourable to the characteristic formation of a 'lake' of cold air.

As higher air temperatures are related to lower positions (and vice versa) along the urban parts of the route, however, there appears to be a negative correlation between temperature and height above sea level. Variability of air temperature in this part of the study area is a typical example of mutual interactions in complex orography and urban/rural land cover, forming either hot or cold spots in the urban temperature field. More detailed quantification of these effects, however, would need more detailed measurements including vertical temperature profiles.

The importance of individual factors for air temperature variability was estimated by correlation analysis (Fig. 5). NDVI emerged as the most important factor, especially in spring and summer, when it explained 20\%-50\% of air temperature variability. Although the importance 


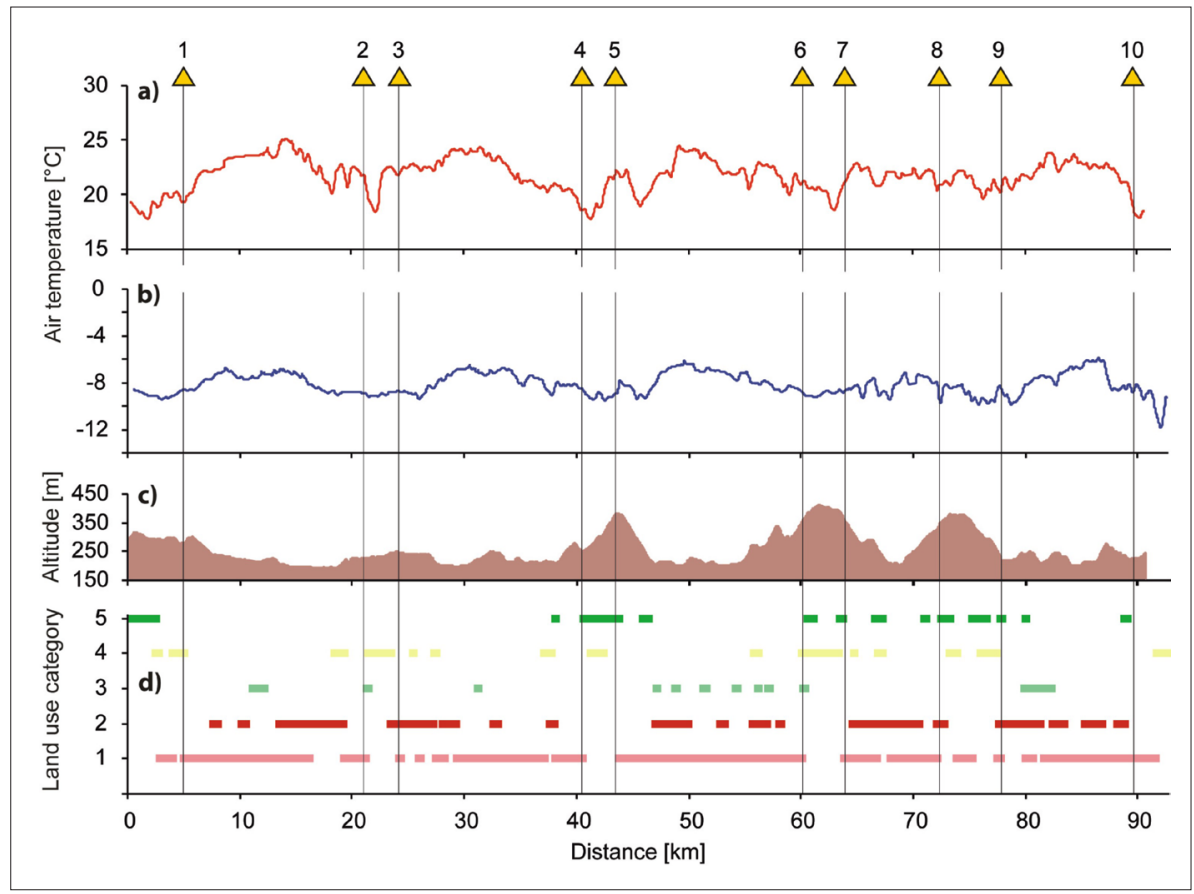

Fig. 4: Air temperature variability along mobile transects: a) 8 July 2011; b) 31 January 2012; c) elevation profile; d) distribution of main land use categories. Verticals 1-10 indicate the positions of reference points from Fig. 1: see Fig. 1 for land use categories. Source: authors' calculations

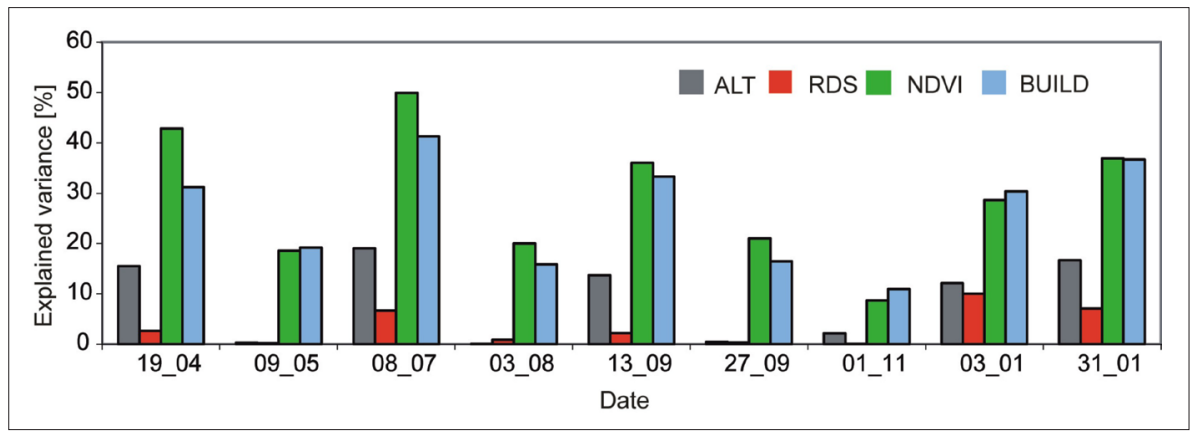

Fig. 5: Air Temperature variability explained $\left(r^{2}\right)$ in terms of: height above sea level (ALT); density of roads (RDS); normalized difference vegetation index (NDVI); and density of buildings (BUILD), in the Brno area in nine different periods from April 2011 to January 2012.

of the BUILD parameter increased in winter, r-squared coefficients $\left(\mathrm{r}^{2}\right)$ for NDVI and BUILD were comparable even in winter $(30 \%-40 \%)$. The correlation between air temperature and percentage of roads (RDS) was low and generally non-significant. This may be related to the fact that RDS represents only a fraction of the impervious surfaces and its spatial distribution does not reflect the degree of anthropogenic transformation well, compared to the BUILD parameter. High or low RDS values may be found in different parts of the study area depending on the spatial configuration of the transportation system. Ambiguous results were found for altitude (ALT). There were high and significant negative correlations in five measuring terms; however, the amount of explained temperature variance was less than $20 \%$ in all terms.

The results of the correlation analysis demonstrated that the two most important factors are the quantity of vegetation and the percentage of built-up areas. Relatively high and significant correlations also facilitate the construction of a regression model conducive to air temperature interpolation from NDVI values, since NDVI covers the whole study area. Even though the mobile temperature measurements provide relatively good coverage, especially in the centre of the study area, interpolation based on only mobile temperature measurements would be partly biased, especially farther from the city centre. In order to overcome this bias and utilize the correlation analysis results, NDVI was used as a covariate within co-kriging of spatial interpolation. Co-kriging is a geostatistical approach to interpolation that makes for better estimation of the values of the main variable of interest (in this case, air temperature) if the distribution of one or several secondary variables is known more precisely due to, for example, better sampling (Cressie, 1993). In co-kriging, autocorrelation of the main variable of interest and all cross-correlations between the main and secondary variables are used to make more reliable predictions.

In the first step, mobile temperature measurements aggregated to the 300 grid cells were standardized to z-scores of zero mean and unit variance. This was done for all nine measurement terms analysed. Standardization allowed direct comparison of temperature measurements taken in different seasons under different temperature regimes. After this, standardized values from individual terms were 
interpolated using co-kriging and the NDVI map as the most significant covariate. Finally, all nine interpolated fields were averaged to a single map (Fig. 6).

A typical air temperature distribution places the highest values in the central part of the city with the least vegetation cover and highest density of buildings. Temperatures drop radially, in general, from this core towards peripheral areas. The decreasing trend is less marked towards the north and east, in parts of the city with a relatively higher density of surfaces of anthropogenic origin. The lowest values occur in the western part of the study area, where elevations are higher and a higher proportion of natural surfaces prevails. Relatively lower z-scores occur in the deeper valleys not far from the central part of the study area. Markedly higher values are related to densely-populated suburbs even when these are situated at relatively higher elevations than the central part of the city. The mean spatial distribution of air temperature (Fig. 6a) is completed with the mean variability computed from all measurement campaigns as well (Fig. 6b), and this map may partially validate our model. Less variable and thus more precise air temperature estimates are typical for the city centre, while higher variability occurs on the periphery.
The mean distribution of the z-scores from Fig. 6, presenting the relative variability of air temperature, may be combined with the real temperature regime disclosed by mobile measurements (summarized in Table 1). The two pieces of information may then be used for estimation of the typical temperature distribution during the evening hours and also to establish UHI intensity in the Brno area. As follows from Table 1, three out of nine campaigns (July 8, August 3, and September 13) took place in hot weather, when mean temperatures measured along the profiles reached $21{ }^{\circ} \mathrm{C}-22{ }^{\circ} \mathrm{C}$, with non-significant differences in temperature variability in terms of an F-test (standard deviations ranged between $1.4{ }^{\circ} \mathrm{C}$ and $1.6^{\circ} \mathrm{C}$ ). Moreover, the main features of the synoptic situation during these three periods were associated with a low-pressure system over Western Europe, contributing to the transport of relatively warm air to central Europe from the south-west. Such situations, especially when they are prolonged by a blocking anticyclone in central and Eastern Europe, are favourable to the occurrence of hot days in central Europe and to the formation of UHI in urban environments. Z-score maps from the three periods were averaged and transformed back to real temperatures using $21.5^{\circ} \mathrm{C}$ as a mean and a standard

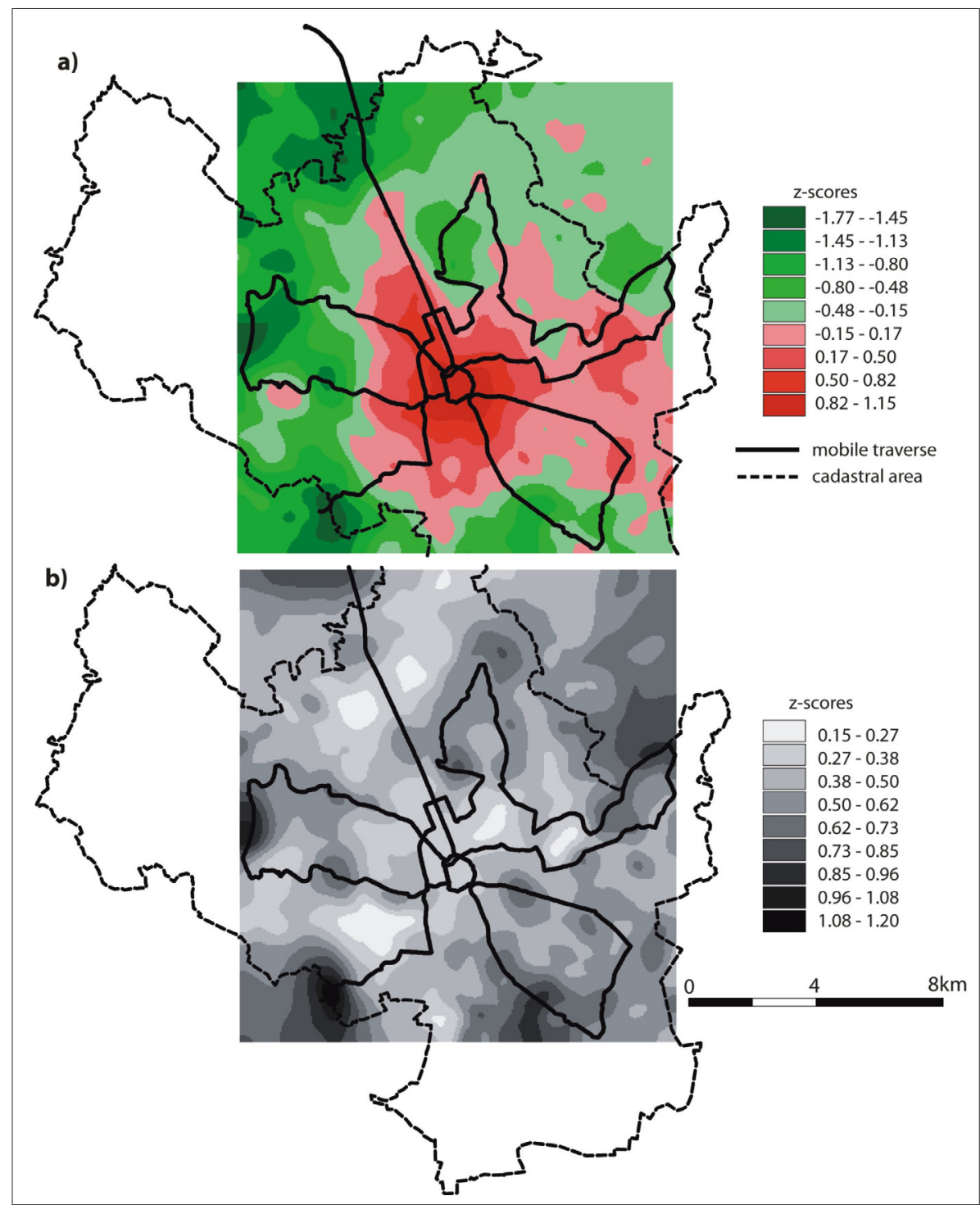

Fig. 6: a) Spatial distribution of early-night air temperatures in the Brno area (calculated as a mean from nine mobile measurements); b) Temperature variability. Interpolated temperatures and their variability are expressed in the form of standardized values (z-scores). Source: authors' calculations 
deviation of $1.5^{\circ} \mathrm{C}$. The resulting map was expressed in the form of temperature anomalies calculated as the difference between temperatures of individual grid-cells in the whole study area and the mean temperature of all grid-cells outside the cadastral area, representing the rural environment; the cadastral area is shown in Fig. 3. This map (Fig. 7) may be considered as an assessment of UHI intensity that occurs during the evening hours on typically hot days in the summer in the Brno area.

The overall features of the spatial distribution of temperature anomalies in summer are largely identical to those presented in the form of the mean field constructed for all nine mobile measurements in Fig. 6. The highest temperatures concentrate around the city centre and extend from there towards the north-west. Local maxima are clearly distinguishable for most of the suburbs. The lowest values occur in a number of spots in the western part of the Brno area. Calculations derived from the temperature anomalies indicate that the city centre may be around $2{ }^{\circ} \mathrm{C}$ warmer than the peripheral parts and about $5{ }^{\circ} \mathrm{C}$ warmer than rural areas in the immediate environment.

\section{Discussion}

Carefully pre-processed temperature measurements and a relatively detailed spatial dataset for four different variables allowed us to evaluate the effects of the latter factors on the spatial variability of air temperature in a medium-sized city in central Europe. Our results are in agreement with similar studies that conclude that the quantity of vegetation (represented by NDVI), and partly the percentage of builtup areas, are the most important factors affecting the spatial distribution of air temperature in urban areas (Unger et al., 2011). The crucial influence of vegetation cover on the spatial variability of air temperature within an urban environment has been confirmed, for example, by Hedquist and Brazel (2006). They used a Soil Adjusted Vegetation Index rather than NDVI for analysis of the temperature field in Phoenix (Arizona). According to Hart and Sailor (2009), canopy cover represented by NDVI was the primary factor in a tree-structured regression model for UHI intensity estimate in the Portland (Oregon) metropolitan area. More relevant results for direct comparison with this study may be found for Szeged (Hungary). Bottyán et al. (2005) used NDVI as a key factor in categorising the main land-cover influences on forming UHI intensity, but they did not quantify the role of NDVI directly.

As the vegetation distribution in cities may be mapped relatively easily and repeatedly from remotely-sensed data, this finding may have important consequences for practical applications in urban climatology, such as the identification of hot-spots and the prediction of air temperature. It may also help to optimize processes in regional planning. Areas with low vegetation (lowest NDVI values) and densely built-up areas (highest BUILD values) clearly highlight the warmest parts of the city. Moreover, their spatial distribution agrees with an analysis of the spatial distribution of land surface temperatures and with surface urban heat island intensity derived from satellite thermal imagery (Dobrovolný, 2012).

In this study, we placed emphasis on making the best possible use of information concerning the extent of impervious areas, combining two original variables (density of buildings and density of roads) into one. This new variable, however, does not provide a higher percentage of explained variance in comparison with the original variables. The sum of built-up areas and road areas explained from 15\% to $38 \%$ of air temperature variability. Further improvements in UHI estimates in the near future may consider other factors that characterize the geometry of constructions (Dobrovolný and Krahula, 2012).

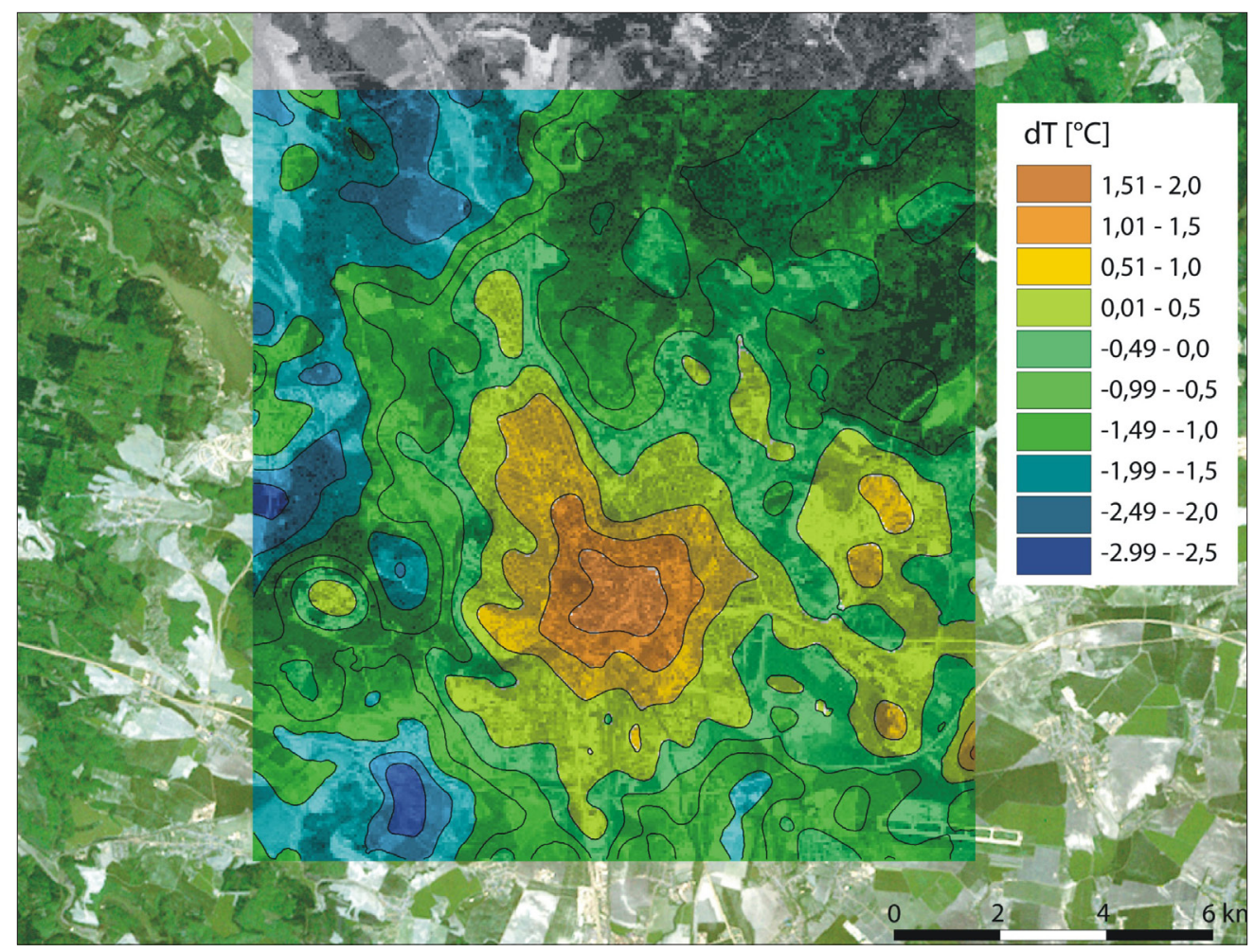

Fig. 7: Spatial distribution of air temperature in the central part of the Brno area in the early night hours: Air Temperature is expressed as deviation (dT) from the mean value of the study area. It is typical of clear, calm weather in the course of a hot day in summer. Source: authors' calculations 
A closer look at our correlation analysis reveals that there exists a clear correlation structure between the explanatory variables used in this study. There exists a highly significant negative correlation between NDVI and BUILD as explanatory parameters. Similarly, there is a significant positive correlation between BUILD and RDS because both measure the degree of anthropogenic influence on local climate. To utilize these cross-covariances, we transformed the original variables to principal components (PC) and tested their relationship to air temperature variability. This type of explanatory data transformation, however, did not provide better correlations to air temperature compared with NDVI. This implies that our air temperature interpolation, based on NDVI values, provided an optimal result considering the available geographical database. Moreover, the simple model of temperature field construction satisfies the principle of parsimony and thus avoids the multicolinearity problem that is typical of multiple regression models. Clearly one source of uncertainly in our approach may be related to the size of the grid employed for unification of all data sets to the same spatial resolution. The $300-\mathrm{m}$ grid may partly smooth local effects and influence correlations. However, this value is comparable to, or even finer than, the grid sizes used in similar studies (Oke, 2006; Unger, 2004; Hart and Sailor, 2009). The relatively weak effect of altitude on air temperature variability suggests that the role of natural factors may be partly suppressed by anthropogenic factors. Moreover, even in the complex terrain of the Brno area, altitudes vary within a relatively low range (less than $250 \mathrm{~m}$ ), rendered even lower in the $300-\mathrm{m}$ grid resolution. Thus the low variation in altitude hampers the establishment of a strong signal.

\section{Conclusions}

Improved knowledge of the effects of selected geographical factors on the spatial variability of air temperature facilitated the use of interpolated air temperature maps for estimation of the UHI intensity that may occur during the early night hours of a typical summer day-cycle. As discussed in Stewart (2011), figures for UHI intensity depend strongly on the methodology used for UHI identification and for its estimation. As our estimate is based on an interpolated temperature field and not on individual sites, this may be considered as a robust feature of this contribution. Our estimate of UHI intensity may also be considered conservative, since it is derived from partly-smoothed data. The instantaneous temperature ranges measured in the course of individual campaigns were mostly higher, reaching $8{ }^{\circ} \mathrm{C}-10{ }^{\circ} \mathrm{C}$ in total in five time periods. The results of this study may be used in various decision-making processes on the part of the Brno city authorities, particularly in the fields of urban planning and regional development, and in various programs addressing urban ecology and the quality of life, especially health.

According to the Fifth Assessment IPCC Report, more frequent and more intense extreme events such as heat waves can be expected in the near future in response to recent climate change (IPCC, 2013). Intensity and duration of heat waves may be further enhanced due to the UHI effect in urban environments, and thus heat waves may have negative impacts, especially on city dwellers. At the same time, the IPCC Report attributes only medium or low confidence to expected future changes in extremes, because of a lack of studies together with data quality issues. This means that many more case studies in various urban areas, based on special-purpose air temperature measurements and detailed geographical databases, are needed. Our study identifies factors that significantly contribute to higher air temperatures, describes spatial and temporal parameters of UHI formation, and finally it estimates UHI intensity in a typical medium-sized central-European city. In summary, we believe that our findings may contribute to a better understanding of urban climate processes and extreme events under recent climate change.

\section{Acknowledgement}

Petr Dobrovolný was supported by Czech Science Foundation project GA205/09/1297; Lukáš Krahula was supported by Masaryk University: project MUNI/A/0952/2013. We also extend our thanks to Tony Long (Svinošice) for his work on the English version of the manuscript.

\section{References:}

ALCOFORADO, M. J., ANDRADE, H. (2006): Nocturnal urban heat island in Lisbon (Portugal): main features and modeling attempts. Theoretical and Applied Climatology, 84(1-3): 151-159.

ARNFIELD, A. J. (2003): Two decades of urban climate research: a review of turbulence, exchanges of energy and water, and the urban heat island. International Journal of Climatology, 23(1): 1-26.

BOTTYÁN, Z., KIRCSI, A., SZEGEDI, S., UNGER, J. (2005): The relationship between built-up areas and the spatial development of the mean naximum urban heat island in Debrecen, Hungary. International Journal of Climatolology, 25(3): 405-418.

CRESSIE, N. A. C. (1993): Statistics for spatial data. Revised edition. Wiley series in probability and mathematical statistics. New York, John Wiley \& Sons.

DOBROVOLNÝ, P. (2012): The surface urban heat island in the city of Brno (Czech Republic) derived from land surface temperatures and selected reasons for its spatial variability. Theoretical and Applied Climatology, 112(1-2): 89-98.

DOBROVOLNÝ, P., KRAHULA, L. (2012): Vliv geometrie zástavby na pole teploty vzduchu a intenzita tepelného ostrova města na př́kladu Brna. Meteorologické zprávy, 65(2): 51-57.

DOUSSET, B., GOURMELON, F., LAAIDI, K., ZEGNOUN, A., GIRAUDET, E., BRETIN, P., MAURI, E., VANDENTORREN, S. (2011): Satellite monitoring of summer heat waves in the Paris metropolitan area. International Journal of Climatology, 31(2): 313-323.

FORTUNIAK, K., KŁYSIK, K., WIBIG, J. (2006): Urbanrural contrasts of meteorological parameters in Łódź. Theoretical and Applied Climatology, 84(1-3): 91-101.

GEORGESCU, M., MOUSTAOUI, M., MAHALOV, A., DUDHIA, J. (2011): An alternative explanation of the semiarid urban area "oasis effect". Journal of Geophysical Research: Atmospheres (1984-2012), 116, D24113.

GRIMMOND, S. (2006): Progress in measuring and observing the urban atmosphere. Theoretical and Applied Climatology, 84(1-2): 3-22. 
HART, M. A., SAILOR, D. J. (2009): Quantifying the influence of land-use and surface characteristics on spatial variability in the urban heat island. Theoretical and Applied Climatology, 95(3-4): 397-406.

HEDQUIST, B. C., BRAZEL, A. J. (2006): Urban, Residential, and Rural Climate Comparisons from Mobile Transects and Fixed Stations: Phoenix, Arizona. Journal of the Arizona-Nevada Academy of Science, 38(2): 77-87.

IPCC (2013): Climate Change 2013: The Physical Science Basis. Contribution of Working Group I to the Fifth Assessment Report of the Intergovernmental Panel on Climate Change (Stocker, T. F., Qin, D., Plattner, G. K., Tignor, M., Allen, S. K., Boschung, J., Nauels, A., Xia, Y., Bex, V., Midgley, P. M. [eds.]. Cambridge University Press, Cambridge, United Kingdom and New York, NY, USA.

KYSELÝ, J. (2010): Recent severe heat waves in central Europe: how to view them in a long-term prospect? International Journal of Climatology, 30(1): 89-109.

LAAIDI, K., ZEGHNOUN, A., DOUSSET, B. BRETIN, P., VANDENTORREN, S., GIRAUDET, E., BEAUDEAU, P. (2012): The Impact of Heat Islands on Mortality in Paris during the August 2003 Heat Wave. Environ Health Perspectives, 120(2): 254-259.

LANDSBERG, H. E. (1981): The urban climate. Academic Press, New York.

OKE, T. R. (1981): Canyon geometry and the nocturnal heat island: comparisons of scale model and field observations. Journal of Climatology, 1(3): 237-254.

OKE, T. R. (2006): Initial guidance to obtain representative meteorological observations at urban sites. IOM Report No. 81, WMO/TD. No. 1250. World Meteorological Organization, Geneva.
PENG, R. D., BOBB，J.F., TEBALDI, C., McDANIEL, L., BELL, M. L., DOMINICI, F. (2011): Toward a Quantitative Estimate of Future Heat Wave Mortality under Global Climate Change. Environmental Health Perspectives, 119(5): 701-706.

QUITT, E. (1972): Měřícíjízdy jako jedna z cest k racionalizaci mezoklimatického výzkumu. Meteorologické zprávy, 6(6): 172-176.

STEWART, I. D. (2011): A systematic review and scientific critique of methodology in modern urban heat island literature. International Journal of Climatology, 31(2): 200-217.

SUNDBORG, A. (1950): Local Climatological Studies of the Temperature Conditions in an Urban Area. Tellus, 2(3): 222-232.

UNGER, J. (2004): Intra-urban relationship between surface geometry and urban heat island: review and new approach. Climate Research, 27(3): 253-264.

UNGER, J., SÜMEGHY, Z., ZOBOKI, J. (2001): Temperature cross-section features in an urban area. Atmospheric Research, 58(2): 117-127.

WENG, Q. (2009): Thermal infrared remote sensing for urban climate and environmental studies: Methods, applications, and trends. ISPRS Journal of Photogrammetry and Remote Sensing, 64(4): 335-344.

YOSHINO, M. M. (1975): Climate in a small area. An introduction to Local Meteorology. Tsukuba, University of Tokyo Press. 